\title{
Yerel Kamu Hizmetleri Bağlamında Etkililik Ölçüm Göstergelerinin Belirlenmesi
}

\author{
Mehtap Çakmak Barsbay ${ }^{1}$ \\ ORCID: 0000-0001-7609-6254
}

\author{
M. Kemal Öktem ${ }^{2}$ \\ ORCID: 0000-0002-2040-426X
}

Öz

Yerel yönetimlerin farklı boyutlar açısından etkin ve etkili olarak değerlendirilmeleri, mevcut kaynaklarm doğru kullanılmasına, hizmet geliştirmeye ve çeşitlendirmeye, yenilikçi yönetim yaklaşımlarının uygulanmasına, sosyal-politik çevreyi oluşturan hizmetten yararlananların ihtiyaçlarına daha çok odaklanmaya bağhıdır. Mevcut girdilerin en uygun şekilde bir araya getirilip yönlendirilmemesi, genel olarak yerel kaynakların yetersizliği ya da yanlış kaynak tahsisi olarak açılanmaktadır. Yerelde hizmet götürülen vatandaşların ve yerel baskı gruplarının beklentileri, yerel yönetimlerin de vatandaş odaklllk yönünde hizmet etme taahhütleri hem ekonomik hem de genel bir sosyo-politik performansin ortaya konulmasın gerekli kılmıştır. Yerelde kamu hizmetlerinin kamu yararı dengesini gözetmesi beklenir. Bu doğrultuda yerel hizmetlerin, salt ekonomik göstergelerden bă̆ımsız ve etkili sunulmamasının tüm paydaşlar açısından sosyal maliyeti olmakta, bu durum hem ekonomik anlamda kaynak israfina hem de hizmet götürülen kesimin, yerel yönetimlere karşı güveninin azalmasına ve nihayeten toplumun desteğini kaybetmelerine neden olabilir. $\mathrm{Bu}$ çalışmanın amacı yerel yönetimlerin, sundukları hizmetlerin etkililik sorununu irdelemektir. Bu kapsamda, yerel yönetim etkililiği, verimlilik, sosyo-ekonomik, sosyo-politik göstergeler bağıntısı incelenmekte, vatandaşın günlük hayat kalitesine etkisi değerlendirilmekte ve vatandaşların ihtiyaçları temelinde bazı göstergelerin kullanımı önerilmektedir.

Anahtar Kelimeler: Etkililik, hizmet kalitesi, verimlilik, yerel hizmet, yerel yönetimler.

\footnotetext{
${ }^{1}$ Dr. Öğr. Ü., Karamanoğlu Mehmetbey Üniversitesi, E-mail: mehtapcakmak@gmail.com

${ }^{2}$ Prof. Dr., Hacettepe Üniversitesi, E-mail: kemalok@hacettepe.edu.tr

idealkent (c) Kent Araştırmaları Dergisi (Journal of Urban Studies) 


\title{
Construction of Metrics to Evaluate Effectiveness in the Context of Local Public Services
}

\author{
Mehtap Çakmak Barsbay ${ }^{3}$ \\ ORCID: 0000-0001-7609-6254
}

\author{
M. Kemal Öktem ${ }^{4}$ \\ ORCID: 0000-0002-2040-426X
}

\begin{abstract}
Some further requirements for better organization of local services, such as fostering public service diversity and improvement, implementing innovative practices in service delivery, focusing on the needs of beneficiaries, are needed to enhance the efficiency and effectiveness of local governments. If and when those required inputs are not combined optimally, it has briefly been conceptualized as a lack of resources and inappropriate resource allocation. Increasing pressures of local community-groups and expectations of citizens, and local governments' commitment to improving the user-oriented public service delivery have generated a demand for performance measurement both in an economic and socio-political manner. Local public officials must act for the balance of public interest. During the service delivery process, acting uneconomically and ineffectively do have social costs for the stakeholders and could lead to waste both available scarce resources and reduced trust towards local governments, in conclusion, lose community support. This study aims to examine the effectiveness of the services, which is supplied by local governments. In this study, we examine the relationship between local government effectiveness, productivity, socio-economic and socio-political indicators and also impact assessment of citizen's daily life quality and attempt to propose some related set of indicators to achieve local outcomes that are responsive to citizen needs.
\end{abstract}

Keywords: Effectiveness, service quality, efficiency, local service, local governments.

\footnotetext{
${ }^{3}$ Asst. Prof., Karamanoğlu Mehmetbey University, E-mail: mehtapcakmak@gmail.com

${ }^{4}$ Proffesor, Hacettepe University, E-mail: kemalok@hacettepe.edu.tr

idealkent @ Kent Araştırmaları Dergisi (Journal of Urban Studies) 


\section{Giriş}

Komün geleneğine dayanarak belirli bir kentsel mekânda yaşayan bireylerin ortak ihtiyaçlarını karşılamak ve ortak sorunlarını çözmek amacıyla oluşturulmuş örgütlü birliktelikler yerel yönetimler olarak adlandırılmaktadır (Ertan, 2002). Bireylerin isteklerini iletebilecekleri en yakın kuruluşlar yerel yönetimlerdir. Yerel yönetimler yerine mahalli idareler, yer yönünden yerinden yönetim kurumları veya âdem-i merkezi yönetim birimleri olarak da ifade biçimi ve kullanımına rastlanmaktadır. Yerel yönetimler, merkezden yönetimin ayrı birer tüzel kişilik vererek özerkleştirdiği, kendi kararlarını verebilecek yetkiye sahip, müstakil bütçesi olan, yerel hizmetlerin hukuka uygunluğunun sağlanmasını garanti altına almak bakımından merkezi idarenin idari (vesayet) denetimine tabi olan yönetim birimleridir.

Yerel yönetimler, vatandaşların güvenine sahip olmadan hayatta kalamaz, görevlerine devam edemezler. Bu nedenle algılanan imajları üzerinde doğrudan etkisi olacak bazı hizmetlere önem ve öncelik vermeleri gerekir (Yang ve Holzer, 2006). Yerel yönetimlerin hizmet sunumunu etkileyecek kararlarında kamu yararı dengesini gözetmesi beklenmekte ve bu doğrultuda yerel hizmetlerin, salt ekonomik göstergelerden bağımsız ve etkili sunulması gerekmektedir. Etkililik göz ardı edilerek sunulan hizmetlerin sağlayacağı sosyal faydadaki sınırlılıklar, paydaşlar açısından yerel yönetimlere karşı güvenin ve ihtiyaç duyulan vatandaş desteğinin azalmasına neden olabilecektir.

Yerelde hizmet götürülen vatandaşların beklentileri ve yerel grupların baskıları, yerel yönetimlerin de vatandaş odaklılık yönünde hizmet etme taahhütleri hem ekonomik hem de genel bir sosyo-politik performansın ortaya konması gerekliliğini ortaya çıarmıştır. Bu nedenle yerel yönetimlerin sundukları hizmetlerin etkililik sorunun irdelenmesi gerekmektedir. Buna karşın, etkililiğin hangi standartlar temelinde, neye göre ölçüldüğü ve bu ölçümün hangi ölçütler (kriterler) temelinde gerçekleştirildiği ve hatta gerçekleşmesi gerektiği konusunda belirsizlikler mevcuttur.

Bu çerçevede mevcut çalışmanın amacı, yerel yönetimlerce sunulan hizmetlerin etkililik sorununu irdelemek, yerel yönetim etkililiği, verimlilik, sosyo-ekonomik, sosyo-politik göstergeler bağıntısını incelemek, vatandaşın günlük hayat kalitesine etkisini değerlendirmek ve vatandaşların ihtiyaçları temelinde bazı göstergelerin kullanımı önerisini ortaya koymaktır. Bu amaçla öncelikle etkililik kavramına, etkililiğin ölçümüne ilişkin sorunlara değinilecek ve ardından yerel yönetimlerin görevleri bağlamında ihtiyaç temelli performans göstergeleri belirlenmeye çalışlacaktır. 


\section{Etkililik Kavramı, Önemi ve Ölçüm Sorunu}

Etkililik, daha ziyade etkinlik kavramı ile ilişkilendirmekte ve verimlilik temelinde açıklanmaktadır. Bazı çalışmalarda ise etkililik, etkinlik ve verimlilik kavramlarının neredeyse aynı anlama gelecek şekilde birbirinin yerine kullanımına sıklıkla rastlanmaktadır. Ancak etkililik, verimlilik ve etkinlik ölçümünden elde edilen bilgiler birbirinden oldukça farklıdır. Etkililik, örgütlerin önceden tanımlanmış amaçlara ulaşmak için gerçekleştirdikleri faaliyetlerin sonunda bu amaçlara ulaşma derecesini belirler (Arslan, 2002) ve genel olarak örgütün gerçekleştirmeyi amaçladıkları ile elde ettikleri arasında yapılan bir karşılaştırmanın ifadesidir. Etkililik, etkinlik ve verimlilikten farklı olarak amaca ulaşmada kullanılan kaynaklara odaklanmaksızın, tümüyle elde edilen sonuçlara (outcome) ve sonuçların yararlılığına (kamu yararı) yöneliktir. Kamu kurumları açısından etkililik, var olma amacını yani misyonunu yerine getirebilmesi ile açklanabilir. Etkililik, beşerî öğeler ile ilişkili olup kurum dışı faktörlerin etkisi altındadır (Kavuncubaşı, 1995). Buna karşılık verimlilik ve etkinlik, örgütsel süreçlerin işleyişi ile ilgili olup teknik ve ekonomik kavramlardır. Yeni kamu işletmeciliği anlayışı ile birlikte yerel yönetimlerde çă̆daş yönetim ilkelerinin uygulanması sürecinde bu kavramlar sıklıkla kullanılmakta, yeni ölçüm araçları geliştirilmektedir.

Farklı sektörlerce sunulan hizmetlerin etkililik göstergelerinin tespit edilmesinde bazı sorunlar bulunmaktadır. Örneğin eğitim hizmetlerinin amacı, mezun öğrenci sayısını artırmak değil öğrencilerde milli eğitimin amaçları doğrultusunda istendik davranış değişiklikleri oluşturabilmektir. Bu gelişim ve değişimlerin ölçümü her zaman mümkün olmadığından etkililik ölçümünde ölçüt olarak hizmet çıtıları kullanılmaktadır. Diğer yandan yerel yönetim faaliyetlerinin takip edilmesinde performans yönetimi tekniklerinden yararlanılmaktadır. Bu amaçla performans göstergeleri aracılığıyla belirlenen zaman dilimlerindeki gelişim potansiyeli ortaya konabilmektedir. Ancak, performans göstergeleri, faaliyetlerin sayısal olarak takibine imkân vermekle birlikte işin ne kadar iyi olduğunu göstermemekte yani o faaliyetin sonuçları ve kalitesi hakkında fikir vermemektedir. Bu nedenle yerel yönetimlerin, kamu yararı doğrultusunda verdikleri yerel hizmetlerin kalitesini ölçmeleri ve değerlendirmeleri gereklidir. Şüphesiz bunları ölçmenin sunulan hizmete, hizmet sunan örgütün niteliğine göre farklılaşabilecek yol, yöntem ve teknikleri bulunmaktadır. Nitekim, hizmet kalitesi ölçüm yöntemlerinin farklı hizmet sektörlerinde uygulanmasina yönelik kapsamlı ve doyurucu bir literatür bulunmaktadır. 
Sunulan hizmete yönelik kalitenin temel olarak, neyin (teknik kalite) ve nasıl (fonksiyonel kalite) sunulduğunun, reklam kampanyaları, halkla ilişkiler çalışmaları, fiyatlandırma ve pazarlama aktiviteleri, gelenekler, ideoloji ve sözlü ifadeler gibi dış etkilerin bir tezahürü olarak ortaya çıan imajın (görünümün), beklenen ve algılanan hizmet arasındaki açıllğı etkilediğine ve dolayısıyla hizmet kalitesinin sağlanması açısından bu boyutlara odaklanmanın gerektiği argümanına dayalı olan Hizmet Kalitesi Modeli, 1984 yılında Grönroos tarafından geliştirilmiştir.

Sunulan hizmete yönelik beklentiler, bireysel farklılık gösterebileceği için detaylı bir şekilde hizmetten yararlananların beklentilerini saptayabilmek gerek zaman gerekse maddi açıdan zorluklar ortaya çıkarabildiğinden (Yılmaz, 2007), hizmet kalitesi ölçeği (SERVQUAL) (Parasuraman, Zeithaml ve Berry, 1988) gibi müşteri beklentileri ile algıları arasındaki farka dayanarak hizmet kalitesinin ölçüldüğü hem özel hem de kamu sektöründeki çeşitli kuruluşlarda kullanılabilecek bir model ortaya konmuştur (Donnelly, Wisniewski, Dalrymple ve Curry, 1995). Model, müşterilerin, hem genel özellikleri ve kaliteli hizmet belirleyicileri ile ilgili beklentilerini hem de belirli bir hizmet sağlayıcı için gerçek ve güncel hizmet kalitesi algılarını ifade edebildikleri varsayımı altında, hizmetin sunulduğu fiziksel tesislerin, kullanılan ekipmanın, hizmet sunan personelin ve kullanılan iletişim mekanizmalarının tanımlandığı gözle görülebilir/somut kriterler boyutu, sunulan hizmetin amacına uygun bir şekilde güvenilir ve tam olarak sunulmasin tanımlayan güvenilirlik kriteri boyutu, hizmeti alanlara yardımo olma ve hızh hizmet sunumunu tantmlayan ihtiyaca cevap verebilirlik düzeyi boyutu, sistemin yetkin, saygll ve güvenli bir hizmet sunumu sağlamasina yönelik güvence vermesi boyutu, hizmetten faydalananlarn ihtiyaçlarm tespit etmeye yönelik çabalarm hizmete erişimi kolaylaştırılmasının sağlandığı empati boyutundan ve bu boyutlara ait kriterlerden oluşmaktadır. Bu boyutlarda tespit edilen hizmet kalitesi açıklarının, müşteri beklentilerinin ne olduğu konusunda müşteri beklentileri ile yönetim algıları arasındaki uçurumu tanımlayan anlayış açı̆̆ı; yönetimin müşteri beklentilerini anlamast ile hizmet kalitesinin tasarım ve özellikleri arasındaki farkı tanımlayan tasarım açı̆̆ı; kilit alanlardaki kaynak sıkıntısı, bağlılık ve motivasyon eksikliği; yetersiz kalite kontrol prosedürleri; ya da yetersiz personel eğitimi gibi nedenlerle ortaya çıkabilecek hizmet kalitesi ve sunulan hizmetin gerçek kalitesi arasındaki boşluğu tanımlayan sunum açığı ve iletişim açığından kaynaklanabileceği ifade edilmektedir.

Hizmet kalitesinin belirlenmesinde hizmetten yararlananların beklentilerini ve aldıkları hizmete yönelik algılamaların ölçmeye ve kullanılan kriter/yöntem(ler)e yönelik getirilen eleştiriler, 1992 yılında Cronin ve Taylor'u 
dört farklı sektörden 660 görüşmeye dayalı olarak elde edilen veriler ile hizmet kalitesinin ölçümünde performansa dayalı bir ölçmenin, SERVQUAL ile hizmet kalitesi ölçümüne göre daha gelişmiş bir yolu olabileceğini, hizmet kalitesinin, memnuniyetin bir öncüsü olduğunu, hizmet kalitesinin memnuniyeti sağlama yerine satın alma niyetini daha az etkilediği sonuçlarını buldukları bir çalışma yapmaya yöneltmiştir. Bu sayede, hizmet sunan örgütlerin performanslarına odaklanarak hizmet kalitesinin belirlenebileceği ortaya konulmuş ve bu amaçla kullanılabilecek hizmet performansı (SERVPERF) ölçeği geliştirilmiştir.

Bu çalışmayı takiben SERVPERF ölçeğinin hizmet sunumunun etkililik ölçümünde daha kullanışlı olduğuna yönelik tartışma (faktörlerin bazı inceleme türünde uygun olamayabileceği açısından) ve çalışmalar ortaya konmuştur. Örneğin, bu bağlamda, Avustralya'da eko-yurtların hizmet kalitesi özelliklerinin araştırıldığı bir incelemede, derinlemesine mülakatlarla, ekoturistlerin eko-yurt ziyaretlerinde önemli gördüğ̈ü kalite boyutları geliştirilmiştir. Bu amaçla SERVPERF hizmet kalitesi performans ölçümü temelli bir ölçek benimsenmiştir. Bu ölçeğin ekoturizm sektöründe uygulanabilirliği s1nanmış ve eko-dostu uygulamalar, eko-etkinlikler ve eko-öğrenme olmak üzere üç ek-faktör özellik saptanmıştır. Konukların eko-turizmde hizmet kalitesi algısını değerlendirmede ve gelecekteki alan araştırmalarında bir çerçeve sunabileceği bulgusu ortaya konmuştur (Ban ve Rooma, 2017).

Etkililik ölçüm göstergeleri bağlamında değerlendirilebilecek bir başka sistem ise farklı sektör, ürün, hizmet ve uygulamaların sunumuna yönelik geliştirilen uluslararası standartlardır. Örneğin herhangi bir ölçek ayrımı gözetmeksizin her tür belediye, yerel yönetim, şehir gibi topluluğun performansını ölçebilmek amacıyla bir araç olarak geliştirilen ve 2018 yılında revize edilerek yeniden yayınlanan 37120 numaralı Toplulukların Sürdürülebilir GelişimiKent Hizmetleri ve Yaşam Kalitesi Göstergeleri standardı, kentlerin ilerleme ve gelişimlerinin sağlanması için kullanılabilecek göstergeleri içermektedir. Standartta, ekonomi, eğitim, enerji, çevre, finans, yangin ve acil müdahale, yönetişim, sağhlk, rekreasyon, güvenlik, barımma, katı atık, telekomünikasyon ve yenilik, ulaşım, şehir planlaması, atık su, su ve sanitasyon, raporlama ve kayıtların güncel tutulması gibi alanlarında 45 temel (anahtar) gösterge bulunmaktadır.

Yerel hizmetlerin standardize edilmesinde 9001 numaralı Kalite Yönetim Sistemi, 14001 numaralı Çevre Yönetim Sistemi, 27001 numarah Bilgi Güvenliği Yönetim Sistemi, 45001 numarah İş Sağhl̆ğ ve Güvenliği Yönetim Sistemi, 18001 numaralı Işs Sağhlğı ve Güvenliği Yönetim Sistemi standartları araç olarak kullanilabilir. 
Etkililik ölçümünde kullanılabilecek araçlardan bir diğeri ise özellikli (spesifik) konulara yönelik göstergeler bütünü olarak nitelendirilebilecek endekslerdir. Örneğin bir ülkenin kalkınma durumunu değerlendirebilecek ve uluslararası karşılaştırmalarda kullanılabilecek ve kapsamında ortalama yaşam süresi, okuryazarlık ve okula kayıt dahil eğitime erişim oranı ve kişi başına düşen gelir göstergelerin bulunduğu İnsani Gelişmişlik Endeksi, ülkelerin sundukları toplam hizmetlerin etkililiğinin ölçümünde kullanılabilmektedir. Sağlık sistemlerinin ve uygulanan sağlık politikalarının etkililiğinin ölçülmesinde, Dünya Sağlık Örgütü'nce oluşturulan Karma Endeks kullanılmaktadır. Benzer şekilde ilerleyen bölümlerde değerlendirmesi sunulan Sürdürülebilir Kentler Endeksi, etkililik ölçüm göstergeleri bağlamında oluşturulmuştur. Sayılan bu yöntemler yanında etkililiğin ölçümünde özellikle kamusal kaynaklara dayalı olarak hizmet sunumunu gerçekleştiren kamu sektöründe, şeffaflık ve hesapverebilirlik kapsamındaki uygulamalar da kullanılabilmektedir.

\section{Türkiye'de Yerel Yönetimler ve Görevleri}

Türkiye'de yerel yönetimlere ilişkin temel hukuki düzenleme 1982 Anayasasi'dır. Bu düzenlemede yerel yönetimlere yönelik olmak üzere iki madde bulunmakta olup bunlar 123. ve 127. maddelerdir. 123. maddede idarenin, $k u$ ruluş ve görevleriyle bir bütün olduğu, teşkilat ve görevleri bakmmindan merkezden yönetim ve yerinden yönetim esaslarna dayandığına yer verilmiştir. 127. maddenin tamamı ise yerel yönetimlere yöneliktir. Buna göre yerel yönetimler (mahalli idareler), "il, belediye veya köy halkını mahalli müşterek ihtiyaçlarını karşılamak üzere kuruluş esasları kanunla belirtilen ve karar organları, gene kanunda gösterilen, seçmenler tarafindan seçilerek oluşturulan kamu tüzel kişileri" olarak tanımlanmıştır.

5302 sayıl İl Özel İdaresi Kanunu'nda il özel idaresi, “il halkının mahalli müşterek nitelikteki ihtiyaçlarım karşılamak üzere kurulan ve karar organı seçmenler tarafindan seçilerek oluşturulan, idari ve mali özerkliğe sahip kamu tüzel kişisi" olarak tanımlanmıştır. Yine 442 sayıl Köy Kanunu'nun 1. maddesinde, "nüfusu iki binden aşağı yurtlar" köy olarak tanımlanmıştır.

Belediyeler (büyükşehir belediyeleri dahil), il özel idareleri ve köyler olmak üzere Türkiye'de üç tür yerel yönetim vardır. İl özel idareleri, belediye ya da köy sınırları içerisinde yer almayan alanlarda görev yapmak üzere her ilde bir tane kurulan yerel yönetimlerdir. Köyler, 2000'den az nüfusu içeren küçük yerleşimlerdir. 
Belediye, şehir belde sakinlerinin yerel ihtiyaçlarını karşılamak için kurulmuş bir yerel yönetim şekli olmakla birlikte Belediye Kanunu'na göre belediyeler, nüfusları ne olursa olsun il ve ilçe merkezlerinde ve nüfusu 5000'den fazla olan yerleşimlerde kurulmaktadır.

Belediyeler, tüzel kişiliğe sahip idari ve mali yönden özerk birimlerdir. Karar verme organları, yerel seçimler yoluyla kendi yetki alanları içinde kendilerine tahsis edilen ortak yerel hizmetleri sağlamak amacıyla oluşturulmaktadir.

5393 sayılı Belediye Kanunu'na göre belediyeler, şehir planlaması gibi yerel ve ortak hizmetler sağlayabilmekte, su ve kanalizasyon sistemleri, ulaştırma, çevre să̆lığı, katı atık, itfaiye, acil yardım, şehir trafiği, ormancılık, parklar ve rekreasyon, konut, kültür ve sanat, turizm, sosyal hizmetler, kadın ve çocuk barnma evleri kurma hizmetleri verebilmekte ve ayrıca diğer kamu kurumlarının sorumluluk alanlarında olmayan görevleri de yerine getirebilmektedirler. Merkezi idare tarafından doğrudan sunulmayan kamu hizmetlerinin yerel düzeyde sunumunda ön planda olan kuruluşlar yerel yönetimlerdir.

Yerel yönetimler, kamu yönetimi içinde halka en yakın olan ve politikalarryla halkın gündelik yaşamı üzerinde doğrudan etkide bulunan önemli bir yönetsel birimdir. Bu bağlamda yerel yönetimler gerek demokrasi anlayış1nın yerleşmesi açısından gerek de yerel hizmetlerin verimlilik ve etkinliğinin sağlanması açısından oldukça önemli kurumsal yapılar (Eryılmaz, 1994) olup halkın ihtiyaçlarını karşılayabildiği ve bir anlamda vatandaş memnuniyetini artırabildiği oranda kuruluş amacını ve temel fonksiyonunu yerine getirmiş olacaktır (Duman ve Yüksel, 2008). Yerel yönetimlerin kendilerine verilen görevleri zamanında ve vatandaşı temel alarak yapmaları öncesinde vatandaşların istek ve beklentilerini doğru tespit etmeleri beklenmektedir. Bu nedenle yerel yönetimlerce sunulan hizmetlerin yerine getirilmesinde vatandaşların ihtiyaçlarının, beklentilerinin ve memnuniyetinin ne derece sağlanabildiğinin belirlenmesi, sorunlu alanlarda düzeltici faaliyetlerin belirlenerek uygulanması yoluyla vatandaş odaklı kamu hizmeti sunulması önemlidir.

Hizmet verdiği nüfus ve hizmet çeşitliliği açısından en kapsamlı olarak değerlendirilebilecek yerel yönetim birimi olan belediyelere yürütülmek üzere verilen görevler, Belediye Kanunu'nun 14. maddesinin a ve b bentlerinde sıralanmıştır. Kanuna göre sunulacak hizmetler aşağıda sıralanmış olup bu hizmetlerin, mahalli müşterek nitelik taşımaları gerekmektedir:

“a) Imar, su ve kanalizasyon, ulaşım gibi kentsel alt yapr; coğrafi ve kent bilgi sistemleri; çevre ve çevre sağhı̆̆ı, temizlik ve katı atık; zabıta, itfaiye, acil yardım, kurtarma ve ambulans; şehir içi trafik; defin ve mezarlkklar; ağaçlandırma, park ve yeşil 
alanlar; konut; kültür ve sanat, turizm ve tanttım, gençlik ve spor, orta ve yüksek öğrenim öğrenci yurtlarl; sosyal hizmet ve yardım, nikâh, meslek ve beceri kazandırma; ekonomi ve ticaretin geliştirilmesi hizmetlerini yapar veya yaptırır. Büyükşehir belediyeleri ile nüfusu 100.000'in üzerindeki belediyeler, kadınlar ve çocuklar için konukevleri açmak zorundadır. Diğer belediyeler de mali durumları ve hizmet önceliklerini değerlendirerek kadınlar ve çocuklar için konukevleri açabilirler.

b) Devlete ait her derecedeki okul binalarmm inşaatı ile bakım ve onarımın yapabilir veya yaptırabilir, her türlü araç, gereç ve malzeme ihtiyaçlarmı karşllayabilir; sağlıkla ilgili her türlü tesisi açabilir ve işletebilir; mabetlerin yapımı, bakımı, onarıminı yapabilir; kültür ve tabiat varlkklar ile tarihi dokunun ve kent tarihi bakımından önem taşıyan mekânlarm ve işlevlerinin korunmasını sağlayabilir; bu amaçla bakım ve onarmını yapabilir, korunması mümkün olmayanları aslına uygun olarak yeniden inşa edebilir. Gerektiğinde, sporu teşvik etmek amactyla gençlere spor malzemesi verir, amatör spor kulüplerine ayni ve nakdì yardım yapar ve gerekli desteği sağlar, her türlü amatör spor karşılaşmalan düzenler, yurt içi ve yurt dışı müsabakalarda üstün başarn gösteren veya derece alan öğrencilere, sporculara, teknik yöneticilere ve antrenörlere belediye meclisi kararıla ödül verebilir. Gıda bankacilı̆̆ yapabilir".

2008 yllında büyükşehirlerde bulunan belde belediyeleri, 5747 sayıl Büyükşehir Belediyesi Sınırları İçerisinde İlçe Kurulması ve Bazı Kanunlarda Değişiklik Yapılması Hakkında Kanun'un 2. maddesi ile kaldırılmıştır. 2012 yılında 6360 sayılı On Dört İlde Büyükşehir Belediyesi ve Yirmi Yedi İlçe Kurulması ile Bazı Kanun ve Kanun Hükmünde Kararnamelerde Değişiklik Yapılmasma Dair Kanun ile büyükşehir belediyelerinin hizmet sunmakla mükellef oldukları hizmet alanları, illerin mücavir alan kapsamına genişletilmiştir. Bu Kanun ile büyükşehir belediyelerinin sayısında artş gerçekleşmiş olup bu alanlar içerisinde bulunan köyler mahalleye dönüştürülmüş ve köy sayısında yarıya yakın bir azalış olmuştur.

Büyükşehirlerde il özel idaresi ve ayrıca büyükşehir olmayan illerde nüfusu 2000'nin altında olan belde belediyeleri de köye dönüştürülmüştür. Bu düzenlemeyi takiben büyükşehirlerde merkeze yakın mahalleler ile merkeze görece uzak mahallelerde yaşayanların hizmete erişim, kendilerine sunulan hizmetleri algılamaları ve dolayısıyla hizmetin etkililiği açısından farklılıkların ortaya çkacağı ileri sürülmektedir. 5216 sayılı Büyükşehir Belediyesi Kanunun 7. maddesinde, büyükşehir ve ilçe belediyelerinin görevleri sıralanmıştır. Bu kapsamda belediyelere verilen görevler şunlardır:

a) Büyükşehir katı atık yönetim planına uygun olarak, katı atıkları toplamak ve aktarma istasyonuna taşımak. 
b) Sihhi işyerlerini, 2. ve 3. sınıf gayrisıhhi müesseseleri, umuma açı istirahat ve eğlence yerlerini ruhsatlandırmak ve denetlemek.

c) Birinci fikrada belirtilen hizmetlerden; 775 sayılı Gecekondu Kanununda belediyelere verilen yetkileri kullanmak, otopark, spor, dinlenme ve eğlence yerleri ile parkları yapmak; yaşlılar, engelliler, kadınlar, gençler ve çocuklara yönelik sosyal ve kültürel hizmetler sunmak; mesleki eğitim ve beceri kursları açmak; mabetler ile sağlık, eğitim, kültür tesis ve binalarnm yapım, bakım ve onarımı ile kültür ve tabiat varlıkları ve tarihï dokuyu korumak; kent tarihi bakımından önem taşıyan mekânlarn ve işlevlerinin geliştirilmesine ilişkin hizmetler yapmak.

d) Defin ile ilgili hizmetleri yürütmek.

e) Afet riski taşıyan veya can ve mal güvenliŏi açısından tehlike oluşturan binaları tahliye etmek ve yıkmak.

Büyükşehir belediye meclis kararı alınması durumunda belediyeler ilaveten aşağıda sıralanan görevleri de yürütmekle mükelleftirler.

a) Yolcu ve yük terminalleri, kapalı ve açık otoparklar yapmak, yaptırmak, işletmek, işlettirmek veya ruhsat vermek.

b) Mezarlık alanlarm tespit etmek, mezarliklar tesis etmek, işletmek, işlettirmek, defin ile ilgili hizmetleri yürütmek.

c) Her çeşit toptancı hallerini ve mezbahaları yapmak, yaptırmak, işletmek veya işlettirmek, imar planında gösterilen yerlerde yapılacak olan özel hal ve mezbahaları ruhsatlandirmak ve denetlemek.

d) Temizlik hizmetleri ve adres ve numaralandırmaya ilişkin görevleri belediye meclisi kararı doğrultusunda müstakilen ya da büyükşehir belediyesi ile birlikte yapmak.

e) Şehir merkezine olan uzaklık, nüfus ve hattı kullanan sayısı kriterleri esas alınarak büyükşehir belediye meclisi kararıla belirlenen yerlerdeki toplu taşıma hatlarının işletmesinin o bölgede kurulu taşıma birlik veya kooperatiflerinden temin edilmesine karar verebilir.

\section{Türkiye'de Yerel Yönetimlere Yönelik Sorunlar ve Beklentiler}

Kentlerde nüfus yoğunluğunun artması, hizmet üretim ve dağıtımının kent düzeyinde yerel yönetimler tarafindan yerine getirilmesini gerekli kıldığı gibi ilaveten, yeni sorunları ve hizmet alanlarını gündeme getirmekte ve yerel yönetimlerin iş yükünü artırmaktadır. Altyapı sorunları, çevre kirliliğ $i$ ve temizliği, să̆lıklı barımma mekanları oluşturma, sosyal hizmetler, suç oranlarında artış sosyal uyumsuzluk, să̆lıklı içme suyu (Yüksel, Bakırcı ve Kutlar, 2011), yaşlı 
nüfusun artması, iç ve dış göç gibi konular ve sorunlar çözüm bulunması gereken hizmet alanları olarak başta gelmektedir.

Literatürde halkın yerel yönetimlerden beklentilerini belirlemeye yönelik birçok çalışmanın yapıldığı görülmektedir (Duman ve Yüksel, 2008; Yücel, Yücel ve Atlı, 2012; Göküş ve Alptürker, 2011; Göküş ve Karayıldırım, 2012; Taşçı, 2014; Uzun ve Çolak, 2015; Candan ve Maltaş, 2015; Etöz, Er ve Kaçmaz, 2016; Örselli ve Bayrakc1, 2017; Özdemir ve Zeren, 2017; Hergüner, 2017). Turan ve Songur (2017) tarafından yapılan araştırmada, Ankara ili Şereflikoçhisar ilçesinde yaşayan halkın genel hizmet beklentilerinin, içme suyu ve kanalizasyon sorununun çözülmesine, belediye katı atıklarmın yönetimine, temizlik hizmetlerine ve yol yapım hizmetine ilişkin olduğunu ortaya koymuştur. Ancak, yerel beklenti ve ihtiyaçlar kentsel mekâna göre farklılık gösterebilmektedir. Örneğin, Çanakkale ilinde vatandaşların belediye hizmetlerinden beklentilerinin kentsel altyapı, toplu taşıma ve engelliler ile toplum merkezlerine yönelik faaliyetlere odaklandığı tespit edilmiştir (Aslan ve Uluocak, 2012; Kozan, Bozgeyikli ve Kesici, 2018). Benzer şekilde Mersin/Anamur Belediyesinden beklentilerin \%75,5'i altyapı hizmetlerinin sağlanmasına yöneliktir (Özdemir ve Zeren, 2017). Uşak ilinde ihtiyacın görece fazla olduğu konuların altyapı, su ve çevre kirliliği hizmetlerine yönelik olduğu sonucuna ulaşılmıştır (Akyıldız, 2012). Ankara Şereflikoçhisar, Çanakkale, Mersin/Anamur ve Uşak özelinde ortak yerel hizmet ihtiyacı alt yapı hizmetlerine yöneliktir.

Etöz vd., (2016) tarafından Alanya'da yapılan araştırmada, katılımcların \%88,8'i belediyelerden iletişime yönelik ve \%50,8'inin ise hizh ve etkin hizmet anlayışı beklentisi içinde oldukları sonucuna ulaşılmıştır. Yerel halkın en çok hizmet beklediği konunun çeore temizliği olduğu, sürdürülebilirliğin sağlanması amacı ile belediyeden katı atı yönetimi, geri dönüşüm ve altyapı konularında fiziki hizmet beklendiği ifade edilmektedir. Duman ve Yüksel (2008) tarafından Mersin ilinde yapılan araştırmada, vatandaşların çöp toplama hizmeti ve içme suyu altyapı yatırımları dışında kalan hizmetlere yönelik beklentilerinin olduğu ortaya konmuştur.

Hizmet kalitesinin ve sunulan hizmetlerin etkililiğinin göstergesi olarak hizmetten yararlananların memnuniyet durumlarından faydalanabileceği söylenebilir. Hizmet kalitesi kavramın, alıcınn gereksinimi ve beklentileri, bunların doğrultusunda hizmette olması gereken özellikler, hizmetin bu özellikler ve niteliklere sahip olma derecesi olarak tanımlamak mümkündür (Esin, 2002). Yerel yönetimlerin vatandaşlara yönelik hizmet sunma görevi yanında yerine getirdiği faaliyetlere yönelik hizmetten yararlananlara bilgi verme görevi de bu- 
lunmaktadır. Aslan ve Uluocak (2012) tarafından yapılan araştırmada, vatandaşların \% 74,6'sının belediye faaliyetlerinden yeteri kadar haberdar olmadığı ortaya konulmaktadir.

Eskişehir ilindeki belediyelerde yapılan bir çalışmada (Filiz, Yılmaz ve Yağıer, 2010) hizmetten yararlananlarm, beklentilerinin altında hizmet algıladiklarn sadece Büyükşehir Belediyesini değerlendirenlerin, fiziksel/somut özelliklerde beklentilerinin üstünde, haberleşme boyutunda ise beklentinin çok altında hizmet aldıkları sonucuna ulaşılmıştır.

2012 yllında 6360 sayıl Kanun'un yürürlüğe girmesini takiben meydana gelen yasal dönüşümlerin vatandaşların beklentilerini, hizmetten memnuniyetlerini ne ölçüde etkileyip değiştirdiğine yönelik yapılan çalışmalardan elde edilen bulgular ile ortaya konan sonuçlar, yerel yönetimlerin etkililiğinin ortaya konması temelinde ele alınabilir. Bu kapsamda 6360 sayılı Kanun ile büyükşehir belediyesi statüsüne kavuşan Trabzon ilinde kapatılan belde belediyeleri bölgesinde sunulan hizmetlerin kalitesindeki değişimi belde sakinlerinin perspektifinden ortaya koyan bir çalışmada (Hergüner, 2017), kapatılan belde belediyelerinin yetkilerinin büyükşehir belediyesine devrinin verimlilik açısından kısmi ilerleme sağlamasma karşın yerel demokrasiyi olumsuz etkilediği belirtilmektedir.

Hatay ilinde 6360 sayılı Kanun öncesi ve sonrası döneme ilişkin hizmetlere yönelik memnuniyet algısının belirlendiği çalışmada (Candan ve Maltaş, 2015), katılımcilarm SERVQUAL ölçeği alt boyutlarından finans boyutu açısindan büyükşehir belediyesi olma sonrası ve öncesi döneme ilişkin memnuniyet düzeyi arasinda istatistiksel olarak anlamlı farklllk bulunduğu, ölçeğin diğer boyutları açsından ise iki dönem arasında memnuniyet algılaması açısından farklılık bulunmadığı ortaya konmuştur. İstatistiksel olarak anlamlı bir fark olmasa da fiziksel, imar, ulaşım ve kültür boyutları bakımından büyükşehir olduktan sonraki dönemde alınan hizmetlere yönelik memnuniyet algısının arttığı, buna karşıllk itimat, sorumluluk, eşitlik, temizlik, denetim ve haberleşme boyutları bakımından memnuniyet algısının azaldığı bulgularına ulaşılmıştır.

Yine 6360 sayılı Kanun öncesi belde belediyesi iken Kanunun yürürlüğe girmesi ile birlikte belediye tüzel kişiliği son bulan Trabzon büyükşehir belediyesi kapsamında mahalleye dönüşen Geyikli ve Söğütlü' de yapılan çalışmada (Uzun ve Çolak, 2015), hizmet sunumu açısından eski dönemin verimlilik, hizmette halka yakınlık, beklentilerin karşılanması, kaynakların etkin kullanımı ve katılım açısından olumlu değerlendirilmesine karşın yeni uygulamadan memnuniyet düzeylerinin görece düşük olduğu ortaya konmaktadır.

Samsun, Antalya, Kocaeli, İzmir, Ankara, Diyarbakır ve Erzurum'da 7000 kişinin kapsama alındığı çalışmada (Okcu vd., 2015), 6360 sayılı Kanun sonrası 
yerel nitelikli hizmet sunumu hakkında hizmetten yararlananların, otogar hizmetleri, mezarlık hizmetleri, mezbaha hizmetleri, hal (sebze/balıkçı) hizmetlerinin büyükşehir belediyesi yerine ilçe belediyesi; su hizmetlerinin, su ve kanalizasyon idaresi; katı atıkların bertarafı, çöplük hizmetleri, ana caddelerin yapım, bakım ve temizliği ve toplu taşıma hizmetlerinin büyükşehir belediyesi; uygulama imar planları ile inşaat ve iskân ruhsat hizmetlerinin ilçe belediyesi tarafından verilmesinden daha memnun oldukları sonucuna ulaşılmıştır.

\section{Sürdürülebilir Kentler ve Kalkınma}

Kentlerin daha sürdürülebilir olması için, çeşitli klasik okumalara bakıldığında yapıl çeore (Tekeli ve Ataöv, 2017), arazi kullanım planlaması, kentsel tasarım, ulaşım, ekolojik ıslah, ekonomik kalkmma, kaynak kullanımı, varlık planlaması, gerçek dünyada sürdürülebilir kent planlaması örnek olayları gibi kuramsal, uygulamalı çalışmalar, vizyon, belirgin ve erişilebilir kaynaklar gibi başlıklara; öğrenciler, mesleki uzmanlar ve kentsel çevrenin geleceğine ilgi duyan vatandaşlar açısından değinen örnekler gözden geçirilebilir (Wheeler ve Beatley, 2004). Kamu yönetimi, toplum ve bölge planlaması ve tasarım ile mimari bölümlerinin akademik iş birliği gerekebilir.

Barınma, ulaşım, çalışma ve boş zamanları değerlendirme gibi dört işlevi olabildiğince yerine getirebilen dünya kentlerinin, sürdürülebilirlik kapasitelerini üst sınırlara taşımalarının yanında sürdürülebilir kent niteliğine sahip olabilmek amaciyla ekonomik, ekolojik ve toplumsal alanlarda dönüşüm, değişim ve kalkınma sağlanmaktadır.

Dünya kentlerine yönelik oluşturulan sürdürülebilirlik karneleri (Sustainable Cities Index, 2016) incelendiğinde, insan başlığı altında demografik (üretim çă̆gndaki nüfus, işgücüne bağımlılı oran, yaşlı nüfus), eğitim, gelir eşitsizliği, iş-yaşam dengesi, suç, sağlık, pahahllık bileşenlerinin; çeore başlı̆̆ altında çeoresel riskler, enerji (kişi başına enerji kullanımı ile Gayri Safi Yurtiçi Hasılanın-GSYİH her bir dolarmı üretmek için tüketilen enerji miktarn), yeşil alanlar, hava kirlilĭgi, sera gazı emisyon düzeyi, atık yönetimi, içme suyu ve sanitasyon bileşenlerinin; ekonomi başlğ̆ altında ise ulaşım altyapısı, ekonomik kalkınma ve refah (kişi başına düşen GSYIH), iş kurabilme kolaylığı (bir işe başlamak için kaç gün ve hangi prosedürlerin gerektiüi, stnır ötesi ticaret kolaylı̆̆ ile bankalardan kredi alma kolaylı̆̆ı), turizm, diğer dünya kentleri ile arasindaki ekonomik ve ticari bağlantı düzeyi, istihdam oranı gibi bileşenlerin kriter olarak kullanılarak bazı kentlere puan verildiği görülmektedir.

Kentlerin değerlendirilmesinde kullanılan göstergeler Tablo 1'de verilmiştir. Söz konusu gösterge puanları bakımından sürdürülebilir kentlerin s1ralaması yapılmıştır. Tüm boyutlar bakımından toplam indeks sıralamasında 
Zürih (İsviçre), Singapur (Singapur), Stokholm (İsveç), Viyana (Avusturya) ve Londra (İngiltere)'nun ilk beşte, Cape Town (Güney Afrika), Manila (Filipinler), Yeni Delhi (Hindistan), Kahire (Mistr) ve Kolkata (Kalküta- Hindistan) ise son beşte yer aldığ 1 listede, İstanbul 77. sırada yer almaktadır.

İnsan alt başlığında yer alan göstergeler bakımından ilk beşte Seul (Güney Kore), Roterdam (Hollanda), Hamburg (Almanya), Viyana (Avusturya) ve Berlin (Almanya)'in; İstanbul'un ise 90. sirada yer aldı̆̆ listede, son beşte Meksiko City (Meksika), Sao Paulo (Brezilya), Nairobi (Kenya), Johannesburg (Güney Afrika) ve Cape Town (Güney Afrika) yer almaktadır. Çevre boyutu bakımından alınan puanlar sıralandığında ise Zürih (Isviçre), Stokholm (Isveç), Cenova (İtalya), Viyana (Avusturya) ve Frankfurt (Almanya)'un ilk beşte, Abu Dabi (Birleşik Arap Emirlikleri), Dubai (Birleşik Arap Emirlikleri), Pekin (Çin), Doha (Katar) ve Kolkata (Hindistan)'nın son beşte yer aldığı listede, İstanbul 74. sırada yer almaktadır. Ekonomi boyutu bakımından yapılan sıralamanın ilk beşinde Singapur (Singapur), Hong Kong (Çin), Londra (İngiltere), Dubai (Birleşik Arap Emirlikleri), ve Zürih (Ísviçre) yer alırken Yeni Delhi (Hindistan), Amman (Ürdün), Kahire (Misır), Bengaluru (Hindistan) ve Kolkata (Hindistan) son beşte yer almakta olup İstanbul 75. siradadir.

Tablo 1. Sürdürülebilir şehirler endeksinde kullanılan göstergeler

\begin{tabular}{|c|c|c|}
\hline GŌSTERGE ADI & GŌSTERGE TANIMI & BASTLIK \\
\hline Eğitim & 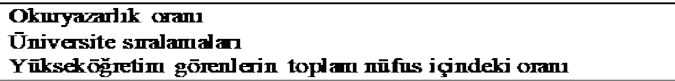 & İnsan \\
\hline Sağlık & $\begin{array}{l}\text { Doğuşta yaşam beklentisi } \\
\text { Obejite orami }\end{array}$ & İnsan \\
\hline Demografi & B ağımlı nūfus oran & İnsan \\
\hline Gedir eşitsizliği & Gini katsaysi & İnsain \\
\hline Pahal luk & $\begin{array}{l}\text { Tüketici fyatlan endeksi } \\
\text { Emlak fyatlan }\end{array}$ & İnsan \\
\hline İş-yał̧am dengesi & Y llık ortalama çal ફ̧ma santlei & İnsan \\
\hline Suç & Cinayet oranı & İnsan \\
\hline Çeviesel riskler & Doğal afet maruziyeti & Cevre \\
\hline Yeşil alanda & Y çil alanlann toplam şehir alanma oramı & Cevre \\
\hline Enejij & $\begin{array}{l}\text { Eneji kullammi } \\
\text { Yenilenebilir eneji kullanumı } \\
\text { s barmda GSYİH başma enejji tüketimi }\end{array}$ & Cevre \\
\hline Hava kidiliği & Ortalama kinetici seviyesi & Cevre \\
\hline Sera gand emisyonu & Metrik tonlardaki misyonlar (kişi başma) & Cevre \\
\hline Atuk yōnetimi & Katı atık yōnetimi (toplanan ọōplerin gen dōnūştūnūme dīxeyi) & Cevre \\
\hline $\begin{array}{l}\text { İçie suyu ve } \\
\text { samitasyon }\end{array}$ & 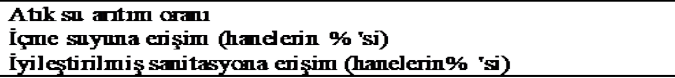 & Cevre \\
\hline Ulaşım altyapısı & $\begin{array}{l}\text { Trafk yoğunduğu } \\
\text { Demiryolu altyapısı } \\
\text { Havaalami memmuniyeti }\end{array}$ & Ekonomi \\
\hline Ekonomik kalkmuma & Kişi başma GSYİH & Ekonomi \\
\hline & İş yapmı kolaylığı endeksi & Ekonomi \\
\hline Twizim & Uhuslarăası ziyaretçi başma ynlluk, mutlak ve kişi başma gelix & Ekonomi \\
\hline Bağlantı & $\begin{array}{l}\text { Mobil bağlantı } \\
\text { Yūksek huzh intemet erişimi } \\
\text { Diğer dünya kentlei ile arasmdaki ekonomik ve ticai bağlant } \\
\text { dūzeyi }\end{array}$ & Ekonomi \\
\hline İstihdam & Çal қ̧an sayısı, şehir nūfusunun \% 'si & Ekonomi \\
\hline
\end{tabular}


Siemens, 16 nicel (kişi başına karbondioksit-CO2 emisyonu, kişi başına su tüketimi, geri dönüşüm oranları ve hava kirletici konsantrasyonları gibi) ve 14 nitel (şehrin daha fazla yenilenebilir enerji, trafik tıkanıklığı azaltma politikaları ve hava kalitesi kodları tedarik etme konusundaki taahhüdü gibi) göstergeyi kullanarak Yeşil Kent İndeksi oluşturmuş ve tüm kıtalardan 130 farklı şehri dahil ederek genel indeks ile farklı alt bileşenler bakımından sıralamalar ve şehirler arası karşılaştırmalar yapmıştır.

Endeks kriterleri ve göstergeleri Avrupa için $\mathrm{CO}_{2}$ emisyonu ve yoğunluğu, $\mathrm{CO}_{2}$ azaltma stratejileri, enerji (enerji tüketimi, enerji yoğunluğu, yenilenebilir enerji tüketimi, temiz ve etkili enerji politikalar), binalar (ikamet amactyla kullanılan binaları enerji kullanım düzeyleri, binalarda enerji verimliliği standartları, binalarda enerji verimliliği teşvik uygulamalar), ulaşım (motorlu araç dışı taşımacılı̆̆ı kullanım düzeyi, yeşil ulaşımın teşvik edilmesi, trafik azaltma uygulamalarn), su (su tüketimi, sistem sizintıları, atı su arıtma sistemleri, su verimliliği uygulamaları), atık yönetimi ve arazi kullanımı (belediye atı üretimi, atıklarn geri dönüşümü, atık azaltma politikaları, yeşil arazi kullanım politikalarn), hava kalitesi (günlük nitrojen dioksit düzeyi, günlük sülfür dioksit düzeyi, günlük tespit edilen partikül madde seviyesi, temiz hava politikası) ve çeore yönetimini (yeşil eylem planı, yeşil politika uygulamalarına kamunun katılımı, yeşil yönetimi) kapsamaktadır. Toplu taşıma araçlarına ortalama 350 metre mesafede yaşanan ve nüfusun yarısı bisiklet kullanan Kopenhag (Danimarka), Avrupa Yeşil Şehirler Endeksi (2009) sıralamasında genel sonuçlar itibariyle 87,31 puan ile birinci sırada yer alırken İstanbul (Türkiye) 45,20 puan ile Avrupa Şehirleri Endeksi'nde 25. sirada bulunmaktadır. Yeşil kentsel alanların (Çelik, 2018) artmasının sürdürülebilirliğe katkısı olduğu gibi sağlığa da önemli etkileri bulunmaktadır. Dünya Sağlık Örgütü, küresel ölümlerin \%3,3'ünün kentlerdeki rekreasyon alanlarına erişim eksikliğine bağlı fiziksel hareketsizlik kaynaklı olduğunu ortaya koymaktadır. Bunun yanında kentlerdeki sağlık risklerinin iklim, hava kirliliği, barınma, sağllksız beslenme, sağglksız içme suyu, çevre temizlĭginin yetersizlĭgi ve kötü atık yönetiminden kaynaklandığı belirtilmektedir.

Herhangi bir ölçek ayrımı gözetmeksizin her tür belediye, yerel yönetim, şehir gibi topluluğun performansını ölçebilmek amacıyla bir araç olarak geliştirilen ve 2018 yllında revize edilerek yeniden yayınlanan uluslararası 37120 numarah Topluluklarm Sürdürülebilir Gelişimi-Kent Hizmetleri ve Yaşam Kalitesi Göstergeleri standardı, kentlerin ilerleme ve gelişimlerinin sağlanması için kullanılabilecek göstergeleri içermektedir. Standartta, ekonomi, eğitim, enerji, çeore, finans, yangın ve acil müdahale, yönetişim, sağllk, rekreasyon, güvenlik, barımma, katı atık, telekomünikasyon ve yenilik, ulaşım, şehir planlaması, atık su, su 
ve sanitasyon, raporlama ve kayıtlarn güncel tutulması gibi alanlarında 45 temel (anahtar) gösterge bulunmaktadır.

\section{Sonuç ve Değerlendirme}

Bu çalışmada, etkililiğin ölçüm yöntemleri değerlendirilmiş ve yerel hizmetler bağlamında kullanımları irdelenmiş olup örgütlerin, misyonları ölçüsünde gerçekleştirmeyi amaçladıkları ile bu amaçlara ulaşabilme ve buna yönelik fayda/kamu yararı ortaya koyabilme derecesini belirlemek için çeşitli yöntemler kullanıldığı, özellikle yerel yönetimlerin faaliyetleri bağlamında vatandaş beklentileri ile memnuniyetlerini belirlemeye yönelik vatandaş karneleri gibi yöntemlerin etkililik ölçümünde tercih edildiği görülmektedir.

Etkililik ölçüm yöntemlerinin, kamu hizmet sunumunda işletmecilik tekniklerinin benimsenmeye başlandığı 1980'lerde geliştirilip kullanılmaya başlanması, neo-liberal politikaların hakimiyetinin bir tezahürü olduğu değerlendirilebilir. Hizmetten yararlananların talep ve beklentilerinin dikkate al1nıp memnuniyetlerinin sağlanması kaygısıyla ortaya çıkan gelişmeler, kamu hizmeti kalitesinin sorgulanıp iyileştirilmeye çalışılması ile eş zamanlı ilerlemektedir.

Sektör ayrımı gözetmeksizin yapılan etkililik ölçüm çalışmalarının, vatandaş odaklı yönetim anlayışı temelinde gerçekleştiği ortadadır. Çalışmada, yerel yönetim etkililiği temelinde kullanılabilecek göstergeler önerilmiş ancak etkililik ölçüm göstergeleri, yerel yönetimler tarafından sunulan hizmetlerle sinırlandırılmıştır.

Etkililik ölçümleri, hizmet sunan örgütlerin spesifik özellikleri bağlamında geliştirilebilir. Etkililik ölçümünde kurumun performansına odaklanan çalışmaların, ölçüt olarak hizmet çıtılarmı ve hizmet sunum sürecine yönelik standart ve göstergeleri; hizmeti alanların memnuniyetine odaklanan çalışmaların ise vatandaş beklenti ve algıların kullandıkları görülmektedir. Etkililik ölçümü bağlamında geliştirilen endekslerin ise hizmet sunan ve alanlara yönelik göstergeleri harmanlayarak bütüncül bir şekilde ortaya koyduğu değerlendirilmektedir.

Yerel yönetimlerin etkililiği bağlaminda göstergeler belirlenirken yerel yönetimlerin bulunduğu coğrafi bölge, hizmet sunulan nüfus, üretim çă̆ındaki nüfus, istihdam düzeyi, yaşlı ve çocuk oranı, işsizlik oranı, ne eğitimde ne istihdamda olan nüfus, ihtiyaç duyulan sektör, alan ve işyerleri için gerekli meslek kazandırma faaliyetlerinin organizasyonu ve yararlanan sayısı, eğitim düzeyi, kreş ve yararlanan sayısı, yaşh merkezleri ile yararlanan sayısı, kişi başına düşen yeşil alan miktarı, engelliler için merkezler ve yararlanan sayısı, iç ve dış göç oramı, kadın, çocuk, engelli ve göçmenler için 
sosyal hizmet merkezleri ve yararlanan sayısı, şehir içi toplu ulaşım araçları, çeşitliliği ve yararlanan sayısı, spor alanlarının sayısı ve çeşitliliği, atık yönetimi merkezleri, çeşitliliği ve sayısı, geri dönü̧̧ümü gerçekleştirilen atık miktarı, sağlık kurumlarnndan teslim alınan tıbbi atık miktarı, artılan atık su miktar, hastane ve evsel atık sularm birbirine karıştırılmadan artıllip arıtılmadığ ve miktarı, imar ve işyeri açma ruhsat sayısı, finansal göstergeler, sanat göstergeleri, yerel yönetimlerde görev yapan personelin eğitim altyapısı ve iş tecrübesi, akıllı kent uygulamaları ile coğrafi ve kent bilgi sistemi alt yapısı, okul binası onarım ve inşaat sayısı, tarihi ve kültürel varlkklar ile bunlarm aslınin korunarak bakım onarım durumu dikkate alınmalıdır.

Yerel yönetimlerin, topluma en yakın hizmet birimleri olarak hizmet üretirken mevcut kaynakları doğru kullanmaları, sundukları hizmetleri geliştirip çeşitlendirmeleri, yenilikçi yönetim anlayışıyla hizmetten yararlananların ihtiyaç, istek ve beklentilerine odaklanmaları ve böylece etkili hizmet sunumu sağlayarak kamu yararının maksimize edilmesi ve hizmetlerin sürdürülebilirliğinin sağlanması önerilebilir. Yerel hizmetler ile sınırlı olan bu çalışma, farklı sektörlerde etkililik ölçüm modellerinin uygulanarak sektörel kullanışlılık düzeylerinin ortaya konabileceği karşılaştırmalı araştırmalara ihtiyaç bulunduğunu göstermesi bakımından önemlidir. 


\section{Extended Abstract}

*

\section{Construction of Metrics to Evaluate Effectiveness in the Context of Local Public Services}

\author{
Mehtap Çakmak Barsbay \\ Karamanoğlu Mehmetbey University
}

\author{
M. Kemal Öktem \\ Hacettepe University
}

Local governments are administrative units in which have direct impacts on the daily life of people through its policies, and they need local support and administrative strength. Otherwise, they would be in a position of losing citizen-support and face declining level of trust among citizens. The increase in the population density in cities necessitates the fulfillment of service production and distribution by the local administrations at the city level; in addition, it raises new problems and service areas, and gradually increases the workload of local administrations. For instance, infrastructure, environmental quality, sanitation, creating healthy housing areas, social services, an increase in crime rates, healthy drinking water, an increase of elderly population, migration issues are the main locus areas where solutions should be focused.

This study aims to examine the effectiveness of the local services employing socio-economic and socio-political indicators, assess the impact on citizen's daily life quality, and also attempt to propose some related set of indicators to achieve local outcomes that are responsive to community needs.

Increasing pressures of local community-groups and expectations of the community, and local governments' commitment to improving the user-oriented public service delivery have generated a demand for performance measurement both in an economic and socio-political manner. If and when those required inputs are not combined optimally, it has briefly been conceptualized as a lack of resources and inappropriate resource allocation.

Social costs for the stakeholders could emerge due to providing services uneconomically and ineffectively during the service delivery and could lead to waste both available scarce resources and reduced trust towards local governments, in conclusion, lose community support. Therefore, they should 
give priority to the main public services that will have direct impact on their perceived images.

Some further requirements for better organization of local services, such as fostering public service diversity and improvement, implementing innovative practices in service delivery, focusing on the needs of beneficiaries, should be fulfilled to enhance efficiency and effectiveness of local governments. Local public officials and managers should create solutions to those problems in organizational boundaries in terms of public interest.

With the dominance of neoliberal policies in the 1980s, when business management techniques were adopted in public service delivery, development and use of effectiveness measurement methods have been prevalent both in the national and local level. Particularly, various methods are used to determine the level of public interest and achievement of the purpose of the activities carried out by local governments in line with their missions. Those measuring methods are based on a citizen-oriented management approach. For example, citizen report cards to determine citizen expectations and satisfaction have been used in effectiveness measurement. Moreover, developments that arise with the concern of ensuring the satisfaction and expectations of the community have simultaneously led to the questioning and improvement of the quality of public service.

When determining indicators in terms of the effectiveness of local governments, the geographical region where local governments exist, population, employment level, elderly and children ratio, unemployment rate, neither education nor employment youth population, literacy rate, number of kindergartens and percentage of beneficiaries, percentage of beneficiaries from elderly centers, amount of green area per person, availability of centers for disabled people and percentage of beneficiaries, migration rate, social service centers for women, children, disabled and immigrants and percentage of beneficiaries from disadvantaged communities, urban public transport, diversity and number of beneficiaries from overall social services, number and diversity of sports fields, type of waste disposal in the area, percentage of recycled wastes, amount of medical waste generation per person, percentage of treated wastewater, wastewater treatment processes indicators, the number of zoning permit and establishment licenses, financial indicators, art indicators, training infrastructure and work experience of the personnel working in local administrations, smart city applications, and geographical and urban information system infrastructure, the number of school building repairs and construction, historical and cultural assets, and their original maintenance and repair status should be taken into consideration. 
We suggest that local governments, as the subsidiary units, should effectively use available resources while providing services to the community, develop and diversify their services, focus on the needs and expectations of the individuals with an innovative management approach.

\section{Kaynakça/References}

Adıyaman, Ç. (2012). Türkiye'nin yenilenebilir enerji politikaları. Doktora Tezi Niğde Üniversitesi, Niğde.

Avrupa Parlamentosu [AP]. (2018). Report on the role of EU regions and cities in implementing the COP 21 Paris Agreement on climate change (2017/2006(INI). A80045/2018). 11 Kasım 2018 tarihinde http://www.europarl.europa.eu/sides/getDoc.do?pubRef=-//EP//NONSGML+REPORT+A8-2018$0045+0+\mathrm{DOC}+\mathrm{PDF}+\mathrm{V0} / / \mathrm{EN}$ adresinden erişildi.

Birleşmiş Milletler [BM]. (2016). Paris Anlaşması. (1. Bsm). (I. Özkaya-Özlüer, E. Turhan, F. Özlüer ed.), (Y. B. Çamurdan Çev.) Ekoloji Kolektifi Derneği. 11 Kasım 2018 tarihinde http://ekolojikolektifi.org/wp-content/uploads/2017/11/Paris_Anlasmasi-ISBN-978-605-83799-1-6.pdf adresinden erişildi.

Birleşmiş Milletler [BM]. (2018). World urbanization prospects: The 2018 revision, key facts. 11 Kasım 2018 tarihinde https://population.un.org/wup/Publications/Files/WUP2018-KeyFacts.pdf adresinden erişildi.

Birleşmiş Milletler Kalkınma Programı [BMKP]. (2018) Sürdürülebilir kalkınma hedefleri. 10 Kasım 2018 tarihinde http://www.tr.undp.org/content/turkey/tr/home/sustainable-development-goals.html adresinden erişildi.

Ćetković, S. ve Buzogány, A. (2016). Varieties of capitalism and clean energy transitions in the European Union: When renewable energy hits different economic logics. Climate Policy, 16(5), 642-657. https://www.tandfonline.com/doi/full/10.1080/14693062.2015.1135778 adresinden erişilmiştir.

City of Paris ve Green Parks and Environment Urban Ecology Agency. (2018). Paris climate action plan: Towards a carbon neutral city and \%100 renewable energies. https://api-site-cdn.paris.fr/images/101081 adresinden erişildi.

DGRV. (2016). DGRV annual survey of energy cooperatives: 2015 - Energy cooperatives. 10 Kasım 2018 tarihinde https://www.dgrv.de/weben.nsf/272e312c8017e736c1256e31005cedff/e7b7b885ccf6c6e8c1257e84004f9047 /\$FILE/Survey_Energy_Cooperations_2015.pdf adresinden erişildi.

Enerji Atlası (2018). Enerji atlası. http://www.enerjiatlasi.com/ adresinden erişildi. Enerji ve Tabii Kaynaklar Bakanlığı [ETKB]. (2012). Dünyada ve Türkiye'de enerji görünümü. www.enerji.gov.tr/Dunyada_ve_Turkiyede_Enerji_Gorunumu.pdf adresinden erişildi. 
eni Fransa. (2017). The electricity market in France. 9 Kasim 2018 tarihinde https://www.eni.com/en_FR/products-services/electricity/electricity_market/electricity_market.shtml adresinden erişildi.

Fouquet, R. ve Pearson, P. J. (2012). Past and prospective energy transitions: Insights from history. Energy Policy, 50, 1-7. https://doi.org/10.1016/j.enpol.2012.08.014

Onurbaş-Avcıoğlu, A. (2017) Yenilenebilir enerji kaynakları ve teknolojileri. Ayten Onurbaş Avcıoğluna ait 2017 Ders Notları, Ankara Üniversitesi, Ziraat Fakültesi, Tarım Makinaları ve Teknolojileri Bölümü. https://acikders.ankara.edu.tr/pluginfile.php/18473/mod_resource/content/0/YEN\%C4\%B0LE-

NEB $\%$ C4\%B0L\%C4\%B0R\%20ENERJ\%C4\%B0\%20KAYNAK-

LARI\%20VE\%20TEKNOLOJ\%C4\%B0LER\%C4\%B0\%202.pdf adresinden erişildi.

International Energy Agency (IEA). (2016a). Energy technology perspectives 2016 towards sustainable urban energy systems: Executive summary. https://www.iea.org/publications/freepublications/publication/EnergyTechnologyPerspectives2016_ExecutiveSummary_EnglishVersion.pdf adresinden erişildi.

International Energy Agency [IEA]. (2016b). Energy policies of tea countries: France. 2016 Review. https://www.iea.org/publications/freepublications/publication/Energy_Policies_of_IEA_Countries_France_2016_Review.pdf adresinden erişildi.

International Energy Agency [IEA]. (2018). Key world energy statistics. https://www.iea.org/statistics/kwes/ adresinden erişildi.

International Renewable Energy Agency [IRENA]. (2016a). Note of the director-general renewable energy in urban settings IRENA input to the New Urban Agenda. Twelfth meeting of the Council Abu Dhabi, 1 - 2 November 2016. 23 Ekim 2018 tarihinde https://www.irena.org/-/media/Files/IRENA/Agency/AboutIRENA/Council/Twelth-Council/C_12_DN_2_RE-and-Cities.pdf adresinden erişildi.

International Renewable Energy Agency [IRENA]. (2016b). Renewable energy in cities:International renewable energy agency (IRENA), Abu Dhabi. 23 Ekim 2018 tarihinde http://www.irena.org/-/media/Files/IRENA/Agency/Publication/2016/IRENA_Renewable_Energy_in_Cities_2016.pdf adresinden erişildi.

Klagge, B., ve Meister, T. (2018). Energy cooperatives in Germany-an example of successful alternative economies?. Local Environment, 23(7), 697-716. https://www.tandfonline.com/doi/abs/10.1080/13549839.2018.1436045

Kuittinen, H ve Velte, D. (2018). Mission-oriented REI policies: In-depth case studies Case Study Report: Energiewende. https://ec.europa.eu/info/sites/info/files/mission_oriented_r_and_i_policies_case_study_report_energiewende-de.pdf adresinden erişildi.

le Dû, S. (2017). Towards 32\% renewable energy in 2030: French public policies for renewables. https://www.tresor.economie.gouv.fr/Articles/6d47bddb-1d14-4597- 
8878-785ab59fc529/files/bd6c631e-ba8c-4092-8a95-37e768d3cccf adresinden erişildi.

Ministry of Environment, Energy and Sea of France [MEEM]. (2016, Haziran). Energy transition for Green Growth Act in action: Regions - Citizens - Business. https://www.ecologique-solidaire.gouv.fr/sites/default/files/Energy

Nilüfer İlçe Belediyesi (2018). Yenilenebilir enerji kooperatifi. 15.07.2018 tarihinde http://www.nilufer.bel.tr/haber-4632-nilufer_yenilenebilir_enerji_uretim_kooperatifinde_genel_kurul_heyecani\#PopupGoster[popup]/0/ adresinden erişildi. Ohlhorst, D. (2015). Germany's energy transition policy between national targets and decentralized responsibilities. Journal of Integrative Environmental Sciences, 12(4), 303-322. https://www.tandfonline.com/doi/full/10.1080/1943815X.2015.1125373 adresinden erişilmiştir.

Onurbaş-Avcıoğlu, A. (2017). Yenilenebilir enerji kaynakları ve teknolojileri: Enerji kaynakları Onurbaş Avcıoğluna ait 2017 Ders Notları, Ankara Üniversitesi, Ziraat Fakültesi, Tarım Makinaları ve Teknolojileri Bölümü. Online site: 10 Kasım 2018 tarihinde

Organisation for Economic Co-operation and Development [OECD]. (2016, Ekim). OECD environmental performance reviews: France 2016. Paris:OECD Publishing, http://dx.doi.org/10.1787/9789264252714-en adresinden erişildi.

REN21. (2017). Renewables 2017 global status report. 11 Kasim 2018 tarihinde http://www.ren21.net/wp-content/uploads/2017/06/178399_GSR_2017_Full_Report_0621_Opt.pdf adresinden erişildi.

Seferihisar İlçe Belediyesi (2018). Yenilenebilir enerji kooperatifi. 15.07.2018 tarihinde http://www.seyeko.web.tr/ adresinden erişildi.

Seto, K.C., Dhakal, A., Bigio, H., Blanco, G.C., Delgado, D., Dewar, L., Huang, A., .... , Ramaswami, A.. (2014) human settlements, infrastructure and spatial planning. ( Edenhofer, O., R. Pichs-Madruga, Y. Sokona, E. Farahani, S. Kadner, K. Seyboth, A. Adler, I. Baum, S. Brunner, P. Eickemeier, B. Kriemann, J. Savolainen, S. Schlömer, C. von Stechow, T. Zwickel and J.C. Minx Der.). Climate Change 2014: Mitigation of Climate Change. Contribution of Working Group III to the Fifth Assessment Report of the Intergovernmental Panel on Climate Change içinde (s. 923 1000). Cambridge University Press, Cambridge, United Kingdom ve New York, NY, USA. 10 Kasım 2018 tarihinde https://www.ipcc.ch/pdf/assessment-report/ar5/wg3/ipcc_wg3_ar5_chapter12.pdf adresinden erişildi.

The International Renewable Energy Agency (2017).The International renewable energy statistics. https://www.irena.org/publications/2017/Jul/RenewableEnergy-Statistics-2017 adresinden erişildi.

The World Bank. (2015). Energy imports. tarihinde https://data.worldbank.org/indicator/EG.IMP.CONS.ZS?locations=TR adresinden erişildi.

Van de Ven, D. J. ve Fouquet, R. (2017). Historical energy price shocks and their changing effects on the economy. Energy Economics, 62, 204-216. https://www.sciencedirect.com/science/article/pii/S0140988316303553 adresinden erişilmiştir. 
Van Staden, M. (2017). Sustainable energy transition: Local governments as key actors. (T. S. Uyar, Der.) Towards 100\% Renewable Energy içinde (s.17 - 25). Springer, Cham. https://link.springer.com/chapter/10.1007/978-3-319-45659-1_2 adresinden erişildi.

Vidalenc, E. (2017). Local energy planning in France: a way to reinforce energy transition. European Council for an Energy Efficient Economy için Konferans Bildirisi. https://www.eceee.org/library/conference_proceedings/eceee_Summer_Studies/2017/3-local-action/local-energy-planning-in-france-a-way-to-reinforceenergy-transition/ adresinden erişildi.

Yılmaz, M, (2012) Türkiye'nin enerji potansiyeli ve yenilenebilir enerji kaynaklarının elektrik enerjisi üretimi açısından önemi. Ankara Üniversitesi Çevrebilimleri Dergisi, 4(2), 33-54. 